\title{
Percepções de educadores de creches acerca de práticas cotidianas na alimentação de lactentes: impacto de um treinamento
}

\author{
Perceptions of day care center teachers \\ about daily practices of infant feeding: the impact of training
}

Giovana Longo-Silva ${ }^{1}$

José Augusto de Aguiar Carrazedo Taddei ${ }^{1}$

Tulio Konstantyner ${ }^{1}$

Maysa Helena de Aguiar Toloni ${ }^{1}$

${ }^{1}$ Departamento de Pediatria, Universidade Federal de São Paulo. Rua Loefgreen 1647, Vila Clementino. 04040-032 São Paulo SP.

giovana_longo@yahoo.com.br

\begin{abstract}
This article stresses the importance of the qualification of professionals involved in thefeeding of children in daycare centers, such that they offeradequate food and programs are developed in order to fosterhealthy food habits in infantsfrom birth. Thus, the scope of this paper was to evaluate the impact of a training program for these daycare teachers in their perceptions and practicesin infant feeding. A qualitative approach was used to evaluate the impact of training, with the application of the focus grouptechnique. Sixteen groups were created, eight of whichwere daycare centerswith training and eight without training, the average number of participants being 6 to 11 per institution agedbetween 19 and 66. The discourse of the teachers who took part in the training program is replete with signs of small changes, or at least with the recognition that it is indeed necessary and possible to promote change. The importance of organizing and conducting training programs for the nutritional education of teachers inday care centersis emphasized, with the continuous supervision of the effects of the qualification as a strategy for infant health.
\end{abstract}

Key words Health knowledge, Attitudes and practices, Child day care centers, Infant care, Health educators, Qualitative research
Resumo $O$ artigo apresenta a importância da capacitação dos profissionais envolvidos com alimentação das crianças em creches, para que estes ofereçam alimentos adequados e promovam ações para que os lactentes incorporem práticas alimentares saudáveis desde o nascimento. Desta forma, o objetivo do presente trabalho foi avaliar o impacto de um treinamento de educadores de creches nas percepções e práticas acerca da alimentação infantil. Para avaliação do impacto do treinamento foi utilizada abordagem qualitativa, com aplicação da técnica do grupo focal. Foram realizados 16 grupos, sendo oito com as creches expostas ao treinamento e oito com as não-expostas, tendo em média de seis a 11 participantes por instituição, os quais apresentavam idades entre $19 e$ 66 anos. O discurso das educadoras que participaram do treinamento está pontuado de indícios de pequenas mudanças, ou pelo menos, de reconhecimento de que é preciso e possível mudar. Destaca-se a relevância de elaborar e executar programas de treinamento e educação nutricional para educadores de creches com supervisão contínua dos efeitos da capacitação como estratégia de saúde infantil.

Palavras-chave Conhecimentos, Atitudes e prática em saúde, Creches, Cuidado do lactente, Educadores, Pesquisa qualitativa 


\section{Introdução}

A promoção da alimentação saudável no ambiente escolar tem sido foco de políticas públicas nas áreas de saúde e de educação ${ }^{1}$. Nesta perspectiva, o Fundo Nacional de Desenvolvimento da Educação (FNDE) estabeleceu, em suas normas para a execução do Programa Nacional de Alimentação Escolar (PNAE), diretrizes que incluem a educação alimentar e nutricional no processo de aprendizagem que perpassa pelo currículo escolar, abordando o tema alimentação e nutrição e o desenvolvimento de práticas saudáveis de vida, na perspectiva da segurança alimentar e nutricional, reconhecendo a escola como um espaço propício à formação de hábitos saudáveis e à construção da cidadania².

Dentre as ações propostas para nortear as diretrizes, destacam-se a sensibilização e a capacitação dos profissionais envolvidos com a alimentação das crianças na escola, para que estes ofereçam alimentos adequados e promovam ações a fim de que os escolares incorporem práticas alimentares saudáveis. A promoção da saúde no ambiente escolar deve ser realizada por todos os atores sociais envolvidos no processo: pessoal da saúde, pais, funcionários, direção e, sobretudo o educador, que, no ambiente escolar, é quem auxilia as crianças no momento das refeições ${ }^{3,4}$.

Ressalta-se que em creches, local onde são atendidas crianças de zero a três anos de idade, o educador é o funcionário responsável pelos cuidados higiênicos, de saúde e alimentação, sendo sua função executar o porcionamento dos alimentos, bem como o oferecimento, refletindo seu papel primordial na constituição dos hábitos alimentares infantis ${ }^{5}$. Apesar das políticas e incentivos à adoção de alimentação saudável nas creches, faltam esclarecimentos e ensinamentos voltados para os educadores, que não apresentam na grade curricular de sua formação, disciplina específica sobre cuidados e alimentação infantil ${ }^{6}$. A literatura aponta que os conhecimentos dos educadores estão associados às suas próprias concepções e se baseiam em costumes, valores e crenças sedimentados em experiências e situações vivenciadas, podendo prejudicar a prestação de cuidados em relação à alimentação das crianças ${ }^{7}$. Assim, muitas vezes, educadores repetem práticas não fundamentadas no saber técnico científico, difundindo erros no cuidado que podem prejudicar as crianças.

Esta realidade sobressalta a necessidade de capacitação dos funcionários de creches quanto aos cuidados de saúde e nutrição, gerando a melhoria do sistema de creches como mecanismo público de promoção de saúde. Assim, grande número de crianças receberia melhores condições de atendimento, e, consequentemente, teriam menores riscos de adoecer e desenvolver sequelas associadas a erros nutricionais ${ }^{8}$.

Neste sentido o objetivo do presente estudo foi avaliar o impacto de um treinamento de educadoras de creches nas percepções e práticas acerca da alimentação infantil.

\section{Métodos}

Trata-se de um ensaio institucional randomizado com controle concomitante e tempo de acompanhamento de quatro meses. O presente estudo é parte integrante do "Projeto Crecheficiente - Impacto do treinamento de educadores de creches públicas/ filantrópicas nas práticas higiênico-dietéticas e na saúde/ nutrição dos lactentes" ${ }^{7,9,10}$ cujo objetivo foi capacitar, aperfeiçoar e atualizar os educadores de creches quanto aos cuidados de saúde e nutrição oferecidos aos lactentes e avaliar a aquisição de conhecimentos à respeito das atividades desenvolvidas pelos educadores.

A seleção das instituições incluídas no estudo partiu de 36 creches cadastradas na Coordenadoria de Educação de Santo Amaro, São Paulo, sendo 16 diretas (administração, prédio e funcionários da prefeitura) e 20 indiretas (prédio da prefeitura e administração e funcionários da instituição filantrópica). Destas, foram visitadas oito creches diretas e dez indiretas, considerando a facilidade de transporte e acesso às suas dependências. Após contatos telefônicos e visitas a essas instituições, quatro creches diretas e quatro indiretas foram selecionadas para o trabalho de campo, segundo critérios descritos a partir da metodologia proposta por Beghin ${ }^{11}$. Priorizaramse os seguintes critérios, em ordem decrescente de valor: maior número de lactentes (crianças de zero a 24 meses), maior número de educadores, ausência de intervenção de educação em saúde anterior, segurança na execução da pesquisa e presença de regras de admissão que garantissem $\mathrm{o}$ atendimento apenas às famílias de baixa renda, consideradas aquelas com até dois salários mínimos per capita por mês.

Após a seleção das instituições, quatro creches foram sorteadas para receber a intervenção proposta, sendo duas diretas e duas indiretas, nas quais foi ministrado, para todos os educadores, o curso "Nutrição e saúde de lactentes: treinamento para educadores e gerentes de cre- 
ches" com duração de 40 horas, registrado na Pró-Reitoria de Extensão da Universidade Federal de São Paulo (UNIFESP) ${ }^{12}$.

O conteúdo do curso baseou-se no Manual CrechEficiente, o qual aborda os temas: alimentação, crescimento físico e desenvolvimento neuropsicomotor, atividades diárias na construção de hábitos saudáveis, sinais e sintomas de doenças, doenças infecciosas, doenças não infecciosas e distúrbios nutricionais, acidentes e violência, condições mínimas de funcionamento e cuidados com equipe, instalações, equipamentos e alimentos. Ressalta-se que o desenvolvimento deste Manual foi destinado a educadores e coordenadores de creches, sendo, portanto, de linguagem simples e ilustrativa ${ }^{13}$.

No início do estudo, todos os educadores, bem como demais integrantes da equipe das creches, receberam um exemplar do manual.

A intervenção educativa incluiu quatro aulas expositivas com auxílio de recurso audiovisual, interação com os participantes e discussão do conteúdo proposto. Por questões logísticas, as creches foram divididas em dois grupos para aplicação do treinamento, permanecendo uma creche direta e uma indireta em cada grupo. $\mathrm{O}$ treinamento ocorreu nas paradas pedagógicas mensais, tendo sido ministrado por um pediatra e um nutricionista que se revezavam entre os dois grupos.

Em adição, após cada uma das quatro aulas, duas duplas de nutricionistas devidamente treinadas, realizaram quatro supervisões semanais em todas as creches expostas ao treinamento, totalizando 16 encontros com as educadoras. A finalidade destas visitas foi reforçar o emprego prático do conteúdo ministrado no curso teórico no ambiente de trabalho, por meio da aplicação da técnica observação participante, processo no qual se mantém a presença do observador no ambiente social com o objetivo de realizar uma investigação científica, estando o observador face a face com os observados. Ao participar da prática cotidiana dos educadores, os pesquisadores colhem dados e se tornam parte do contexto sob observação, experienciando e compreendendo a dinâmica dos atos e eventos, e recolhendo informações a partir da compreensão do sentido que os atores atribuem aos seus atos ${ }^{14}$. Esta atividade em campo desvenda os motivos e/ou justificativas das equipes das creches em treinamento em promover ou não alterações nas práticas higiênico-dietéticas desenvolvidas ${ }^{15}$.

Para avaliação do impacto do treinamento das educadoras nas percepções higiênico-dietéti- cas foi utilizada abordagem qualitativa de pesquisa, com aplicação da técnica do grupo focal, tendo sido observadas as principais recomendações com relação a essa técnica, a saber: o grupo deve ser composto, preferencialmente, por, no mínimo, seis e, no máximo, quinze indivíduos; o moderador deve propor as questões aos participantes, mantendo o foco da discussão, realizando sínteses e retomando o assunto, em eventuais desvios $^{16,17}$; o observador deve ter a função de, após a realização do grupo, complementar o relato dos acontecimentos ${ }^{18}$; a amostra deve ser intencional, isto é, composta pelos indivíduos mais adequados quanto à possibilidade de fornecerem as informações úteis para a pesquisa.

As vantagens da utilização da técnica do grupo focal incluem o baixo custo, rapidez, flexibilidade, na medida em que permite obter respostas dos participantes que não estavam previstas pelo pesquisador e, sobretudo, na redução da distância entre os participantes e o pesquisador. Por outro lado, existem algumas limitações, tais como: a impossibilidade de interpretar seus resultados quantitativamente com o objetivo de embasar uma decisão ou de desenvolver normas, já que a amostra não é probabilística e não permite generalizações ${ }^{16,18,19}$.

Um especialista na aplicação da técnica com a ajuda de um auxiliar realizaram oito grupos focais com as educadoras das creches selecionadas, visando levantar informações sobre o conhecimento prévio da prática cotidiana destas educadoras no que se refere à saúde e nutrição. Esta etapa ocorreu em maio de 2007. Entre outubro e dezembro do mesmo ano foram realizados novamente grupos focais (pós-treinamento), com as mesmas educadoras da primeira etapa. Nas quatro creches que participaram do treinamento, procurou-se verificar mudanças na prática cotidiana e aprendizado a partir dos conteúdos recebidos. Nas outras quatro creches, do grupo controle, verificou-se se houve alguma mudança na rotina, se as educadoras participaram de algum curso ou treinamento e qual a importância de uma formação específica para a atividade que executam com as crianças.

O roteiro do grupo focal, aplicado antes e após o treinamento, no grupo exposto e controle, envolveu questões relacionadas a três eixos temáticos: alimentação, higiene e saúde. Visando maior aprofundamento da discussão, optou-se por focar apenas o tema alimentação no presente estudo. Aborda-se ainda como tema diretamente relacionado à alimentação, a formação docente para educação infantil de zero a dois anos. 
Esses temas foram abordados com ênfase no treinamento e a expectativa da equipe era a de que após o treinamento as educadoras manifestassem mudanças a partir do que foi aprendido, tendo sido aplicado similarmente ao grupo não exposto visando permitir um grau mínimo de comparação entre os expostos e os controles.

As reuniões foram gravadas em fita cassete $\mathrm{e}$ transcritas posteriormente, garantindo o sigilo da identidade das educadoras. Pesquisador especialista na técnica procedeu a análise do discurso, que procura obter os núcleos de sentido, ou seja, significado do discutido nos grupos ${ }^{19}$.

O presente estudo foi aprovado pelo Comitê de Ética em Pesquisa da Universidade ao qual está vinculado e participaram da coleta todas as educadoras de crianças de zero a 24 meses que concordaram em participar por meio da assinatura do Termo de Consentimento Livre e Esclarecido (TCLE).

\section{Resultados e Discussão}

Foram realizados 16 grupos focais, sendo oito com as creches expostas ao treinamento e oito com as não-expostas, tendo em média de seis a 11 participantes por instituição. A idade das educadoras variou de 19 a 66 anos e todas as participantes eram do sexo feminino. Entre elas, o período de experiência de trabalho em creches foi bastante heterogêneo, variando de um mês até 28 $\operatorname{anos}^{7}$. Os grupos focais tiveram duração em torno de uma hora e 10 minutos.

A análise dos grupos focais na fase pré-intervenção indicou que não havia diferença significativa entre as oito instituições, tampouco entre as creches diretas e indiretas. Existiu similaridade nas rotinas estabelecidas em cada uma delas, nos perfis dos grupos de educadoras e nas maneiras como descrevem sua experiência. Os relatos das educadoras apontaram que a rotina de trabalho está centrada na higiene e alimentação das crianças, e pouca relevância é dada às atividades pedagógicas e lúdicas.

Situações de conflitos e discordâncias com a família das crianças, particularmente com as mães, estiveram fortemente presentes no discurso das educadoras. $\mathrm{Na}$ opinião destas, as mães consideram a creche como substituta materna e argumentam que qualquer problema de saúde ou higiene das crianças é descaso da mãe, falta de atenção ou desinteresse, mesmo considerando que as crianças permanecem de 10 a doze horas por dia na instituição, durante cinco dias da se- mana. A maternagem surgiu no discurso das educadoras como o elemento que contribui fundamentalmente para a competência e qualificação das educadoras de creches. A maioria citou que escolheu a profissão por gostar de trabalhar com crianças, por dom ou por amor. As educadoras entendem que para proporcionar atendimento mais apropriado precisariam de número menor de crianças por profissional.

$\mathrm{Na}$ análise dos grupos focais, o momento da alimentação surgiu como umas das atividades mais trabalhosas. As dificuldades relacionadas durante os discursos estavam ligadas à introdução dos alimentos, passagem da consistência pastosa para a sólida e ao fato das educadoras serem responsáveis pela oferta dos alimentos às crianças. Na segunda fase dos grupos focais, algumas destas dificuldades apontadas deixaram de ter grande importância uma vez que boa parte das crianças já estava adaptada à rotina e alimentando-se sozinhas.

Ainda que as educadoras mencionem que as crianças estejam se alimentando sozinhas, muitas procuram auxiliá-las para evitar desordem, controlar o tempo da refeição e garantir que elas comam, como evidencia o diálogo:

Educadora: - Brincar com a comida? Jogar fora do prato? Não ahhh.

Educadora: - Não digo joga fora comida, fazer guerrinha, isso também não. Mas a criança pegar a comida com a mão, se lambuzar, cheirar, mexer...?

Educadora: - O certo seria...

Educadora: - Normalmente não, vamos ser bem sinceras. Porque o prazo é muito curto, a gente tem meia hora para dar o almoço, dar a sobremesa, dar a água, levar no banheiro, a gente tem meia hora. Então começou a fazer muita gracinha a gente fala, menino para de brincar e come a comida.

Educadora: - Às vezes a gente está dando a comida para a criança e ela não quer comer. Só quer comer se for sozinha. Se a gente for deixar ela comer do jeito que ela quer vai para tarde e não acaba. Então a gente acaba pegando a colher e dando até mesmo sem ela estar querendo na hora.

Percebe-se que as educadoras têm dificuldades de lidar com a rejeição das crianças a certos tipos de alimentos, e com tempo de trabalho que a introdução de alimentos demanda. E entendem que para garantir que as crianças recebam os nutrientes que as educadoras consideram necessários, vale até enganar.

Tais artifícios contrariam a recomendação de que os alimentos sejam oferecidos em contexto positivo, na qual a criança não seja submetida a 
chantagem, coação ou premiação para induzir o consumo. Muito mais do que o aporte de alimentos nutricionalmente saudáveis, a alimentação neste período representa a formação de hábitos alimentares que refletirão padrões alimentares na vida adulta ${ }^{20,21}$.

Observou-se que as educadoras de todas as creches não participam da elaboração do cardápio e do processo de preparo dos alimentos oferecidos às crianças. Além disso, relataram ter pouco ou nenhum contato com a nutricionista da Prefeitura, pois esta visita a creche esporadicamente. Há casos em que a Coordenadora da Creche, a orientadora pedagógica e a enfermeira têm alguma participação com a Nutricionista nas decisões sobre a alimentação.

As educadoras manifestam interesse em participar das questões relativas à alimentação, porque entendem que conhecem melhor as crianças e suas necessidades, tal como observado no trecho abaixo.

Educadora: - Olha eu acho que da mesma forma que ela passa para a cozinha, devia passar para nós $[. .$.

Educadora: - Para nós entendermos a mudança, porque que não pode, por que tal coisa...

Educadora: - Até em relação quantidade de alimento que se coloca no pratinho, que se oferece à criança.

A ausência de uma forma mais participativa das educadoras nas decisões da creche pode levar a situações irregulares de procedimento, principalmente com relação à alimentação, como descrito a seguir:

Facilitadora: - Vocês não podem dar opinião sobre os alimentos?

Educadora: - Não pode interferir na alimentação.

Facilitadora: - Ah, vocês não podem entrar na cozinha?

Educadora: - Não pode entrar, nem falar.

Facilitadora: - Nunca foi perguntado o que vocês acham?

Educadora: - Vem lá de baixo pronto e você tem que dar o que tá ali. A gente dança conforme a música.

Educadora: - Ninguém pergunta. Se tiver caldo você tem que dar, se não tiver você tem que dar do mesmo jeito. Porque se você for lá e falar, já é confusão.

Educadora: - Eu fui parar na diretoria porque dei uma bolacha para o Pedro, que não gostava da comida.

Educadora: - ...não pode dar. Porque a gente traz a bolacha para tomar o nosso café.
Educadora: - Essa aqui trouxe um pacote de bolacha e disse assim que a comida hoje foi um enjoo, trouxe um pacote de bolachas para dar a eles na hora do leite. Para que? Abriu esse armário aí... a casa caiu.

Educadora: - Uma traz pipoca, pacote de salgadinho, a gente se junta e fica uma na porta, a gente tem que dar a pipoca na mão deles e aí quando vem alguém...

Os discursos das educadoras apresentados neste contexto demonstram que tal prática pode influenciar na formação de hábitos alimentares inadequados, promovendo a integração precoce de alimentos industrializados na dieta destes lactentes. Os resultados do estudo transversal, realizado no âmbito deste projeto, com 270 crianças, que frequentavam os berçários das oito creches constatou que aproximadamente $67 \%$ dos pais ofereceram alimentos industrializados, ainda no primeiro ano de vida, sendo que foram os filhos de mães com baixa escolaridade, mais jovens e com menor renda os mais susceptíveis a esses erros alimentares ${ }^{9}$.

As educadoras compreendem que o momento da refeição é para as crianças desta faixa etária uma atividade lúdica, mas acreditam que precisam auxiliá-las oferecendo o alimento na boca, para garantir que se alimentem e evitar que levem muito tempo. Em algumas das instituições estudadas, os horários das refeições principais são escalonados, uma vez que o refeitório é pequeno para atender todas as turmas.

Tais afirmações corroboram com estudo conduzido com as crianças frequentadoras das creches do presente estudo, que refletiram déficit no consumo alimentar durante a permanência na instituição, sendo a adequação de valor energético correspondente a $49,78 \%{ }^{22}$, valor aquém da recomendação para este grupo etário ${ }^{23,24}$.

Dessa forma, as educadoras acreditam que a alimentação servida poderia ser mais variada e melhor balanceada, com menos gordura, melhor temperada e com equilíbrio entre tipos de alimentos oferecidos para não afetar a digestão da criança e o funcionamento do intestino. Informações semelhantes foram identificadas por Assao e Cervato-Mancuso ${ }^{25}$, que avaliando a percepção de educadores sobre alimentação saudável para crianças identificou que não ter sempre a mesma coisa e oferecer alimentos de diferentes grupos alimentares foram os principais itens citados pelas educadoras.

Foi comum as educadoras mencionarem que o sucesso da boa alimentação na infância está relacionado também aos hábitos alimentares da 
família e que é importante que os pais participem desse processo de introdução dos alimentos sólidos. De modo geral, embora as educadoras tenham contato diário com as mães, na entrada e na saída das creches, e mesmo em reuniões eventuais, alegam que é pequena a participação das mães e responsáveis, refletindo parcialmente sua forte resistência à orientação das educadoras.

Tal discurso foi reforçado também por Dias et al. ${ }^{26}$, ao estudarem as percepções, os valores e as experiências dos cuidadores familiares e de profissionais de uma equipe de saúde da família sobre a alimentação de crianças menores de dois anos de idade. As falas de vários entrevistados apontaram que os pais e a família devem incentivar hábitos alimentares saudáveis e servir de exemplo para os filhos.

É interessante observar que o treinamento teve um impacto positivo para boa parte das educadoras no que se refere a substituir o hábito de misturar os alimentos para a criança ingerir. Nota-se que esse hábito vem da ideia de que o procedimento seria uma forma de garantir a ingestão de todos os nutrientes.

Relatos semelhantes foram observados nos discursos de gestores e coordenadores de creches públicas de Jandira (SP), nos quais se observou também a utilização de recursos como a camuflagem de alimentos para melhorar a aceitação alimentar e o procedimento de misturar os alimentos e oferecê-los juntos. Os entrevistados acreditam que é importante que as crianças comam tudo o que é oferecido para atender as necessidades nutricionais das mesmas ${ }^{4}$.

Além disso, observou-se a aquisição do conhecimento, após o treinamento em relação à importância do ferro na alimentação infantil, da manipulação dos alimentos pelas crianças para reconhecimento de texturas e preferências alimentares e da substituição da mamadeira pelo uso do copo, conforme descrito nos trechos abaixo:

Facilitadora: - Vocês fizeram um curso, e este curso colaborou, o que vocês aprenderam em relação à alimentação?

Educadora: - Aquele mito de que o ferro está no feijão, e foi tirado realmente da cabeça; maior fonte é a carne na verdade.

Educadora: - [...] quais alimentos que realmente o organismo vai absorver o ferro, em relação à alimentação, suprimento da alimentação que é o ferro até os dois anos que a criança tem que tomar [...] porque tem no posto e por muitas vezes o pediatra não orienta a família, até para nós mesmo. Até os 2 anos esta questão assim reforçou não misturar o alimento, acho que deu um olhar diferen- ciado assim na questão de deixá-los pegar com a mão, olhar, experimentar, não só com a colher; a gente sempre fica orientando pega só com a colher, a gente deixa em algum momento.

Facilitadora: - Vocês aprenderam com o curso, isso foi uma mudança resultado do curso, e como está sendo esta mudança, como é que vocês avaliam, está sendo boa, as crianças estão comendo mais?

Educadora: - No começo foi um pouco difícil, mas agora eles se adaptaram.

Educadora: - ...eles estavam acostumados a comer a comida mais molinha, mais batidinha, aí veio mais diferente que veio o feijão, arroz, os grãozinhos...

Educadora:- E da mamadeira para o copo, porque eles tomavam mamadeira, mandaram usar copo.

Facilitadora: - Isto também foi durante o curso? Educadora: - Foi durante o curso.

Facilitadora: - Senão eles estariam tomando mamadeira até hoje?

Educadora: - Até hoje.

Facilitadora: - Vocês notaram diferença, eles estão se alimentando mais, eles estão se alimentando melhor com esta mudança?

Educadora: - Eu acho que sim, não sei se por causa da idade que eles estão maiorzinhos.

Educadora: - Inclusive tem até criança maiorzinha lá que sabe o que é feijão, arroz, carne.

Educadora: - Aí fica sabendo a preferência da criança.

Ao serem questionadas sobre a necessidade de uma formação superior para exercerem a atividade profissional, boa parte das educadoras concorda quanto à importância da profissionalização. Ao mesmo tempo relatam quanto à ineficiência do curso de Pedagogia ou de Magistério Superior em prepará-las para a atividade específica de educadora infantil. As especificidades que envolvem a educação de crianças de zero a dois anos, no que se refere à nutrição e saúde, não são abordados pelos currículos de formação básica. Poucas educadoras têm condições de buscar uma formação complementar para preencher esta lacuna, que eventualmente é complementada com a formação continuada por meio de cursos de curta duração e de treinamentos oferecidos esporadicamente pela Prefeitura. Porém, a participação nestes cursos está condicionada à disponibilidade de tempo e financeira e acesso aos locais onde são oferecidos, sempre com número de vagas inferior à demanda de educadores por treinamento.

Neste contexto, o fato do treinamento do presente estudo ter sido oferecido no próprio 
espaço de trabalho das educadoras e durante o expediente de trabalho, coincidindo com a parada pedagógica mensal das instituições foi avaliado pelo grupo como positivo.

Nota-se que a experiência profissional é constituída para algumas delas pela própria experiência da maternidade, e afirmam ter aprendido a trabalhar com crianças pequenas na prática do dia-a-dia e com o auxílio de outras companheiras mais experientes, práticas aprimoradas pela participação nos cursos de curta duração.

O período de experiência das educadoras em creche, que variou de um mês a 28 anos, poderia se associar a maior ou menor adequação das atividades práticas. A técnica do grupo focal objetiva traduzir o discurso predominante do grupo não permitindo estudo das diferenças segundo características específicas dos participantes, como é o tempo de experiência profissional. Tal variável poderia funcionar tanto promovendo a incorporação e a fixação de atitudes práticas como desfavoráveis para a boa alimentação infantil.

Para a maioria das educadoras do grupo que participou do treinamento, a formação superior é importante como base teórica, mas é consenso de que o curso não prepara para a prática cotidiana com as crianças pequenas. Aquelas educadoras que não possuem curso de Pedagogia tendem a contestar mais enfaticamente a necessidade da formação superior para o exercício do cargo. O discurso das educadoras mostra também uma clara percepção da falta de reconhecimento profissional, da pouca valorização do trabalho realizado na creche pelas educadoras. Essa percepção se revela quando a educadora percebe o descaso de colegas que lecionam no ensino fundamental e na ausência do conteúdo específico de crianças de zero a dois anos no currículo de formação em Pedagogia.

Educadora: - Eu também não sabia de nada, não tive nenhum curso específico, foi a Deus dará mesmo, na prática, aprendi na prática, observando, errando e assim desde que eu entrei, o suporte era pelo menos pedagógico, mais teórico, porque na verdade a gente... o que eu aprendi foi na prática, fazendo... que o teórico veio depois.

Educadora: - Bem eu já conhecia um pouco porque meus filhos frequentavam creche quando eu entrei na Prefeitura, eu aprendi um pouco na creche trabalhando, mas eu já sabia mais ou menos um pouco.

Diante deste contexto, as Diretrizes Curriculares Nacionais para o curso de graduação em Pedagogia (15/05/2006), exige que o egresso do curso esteja apto a compreender, cuidar e educar crianças de 0 a 6 anos, contribuindo para o desenvolvimento, porém não há na grade curricular matéria específica sobre alimentação infan$\mathrm{til}^{6}$, evidenciando a necessidade de treinamentos específicos voltados a este grupo profissional.

Os grupos focais, tanto do grupo controle como do grupo exposto ao treinamento mostraram que as dificuldades relacionadas à alimentação dos lactentes são similares. Observa-se que as educadoras têm pouca participação no processo de construção do projeto educativo e de alimentação das instituições, atuando como sujeitos passivos nos processos pedagógico e nutricional.

O discurso das educadoras que participaram do treinamento está pontuado de indícios de pequenas mudanças, ou pelo menos, de reconhecimento de que é preciso e possível mudar, como observado na questão da alimentação. Ressaltase que a observação de reduzido número de mudanças na prática cotidiana das educadoras, bem como no aprendizado a partir dos conteúdos trabalhados, pode ter sido devido ao intervalo de tempo da aplicação dos grupos focais, que foi de quatro meses, nem sempre suficientes para a incorporação de conhecimentos e realização de mudanças na prática.

Desta forma, os achados aqui evidenciados baseados nos dados qualitativos oferecidos pela técnica do grupo focal sugerem ser plausível considerar real o efeito positivo do treinamento neste ensaio institucional como indicativo de melhoria do atendimento oferecido pelas educadoras participantes.

Neste contexto, destaca-se a importância de elaborar e executar programas de treinamento e educação nutricional para educadores de creches com supervisão contínua dos efeitos da capacitação como estratégia de nutrição infantil. Tal intervenção educacional pode ser reproduzida em creches que atendem populações empobrecidas como uma tecnologia social promissora capaz de superar situações interferentes no processo de aprendizado e modificação de ações.

\section{Colaboradores}

G Longo-Silva e MHA Toloni participaram na concepção, delineamento e redação do artigo; participou na concepção, delineamento e redação do artigo. T Konstantyner e JAAC Taddei participaram na concepção, delineamento e revisão crítica. 
Referências

1. Brasil. Ministério da Saúde (MS). Ministério da Educação (MEC). Portaria interministerial no 1.010 de 8 de maio de 2006 [periódico na internet]. 2006 [acessado 2011 jun 12]. Disponível em: http:// dtr2001.saude.gov.br/sas/PORTARIAS/Port2006/ GM/GM-1010.htm

2. Brasil. Ministério da Educação (MEC). Fundo Nacional de Desenvolvimento da Educação (FNDE). Conselho Deliberativo (CV). Resolução/CD/FNDE no 38, de 16 de julho de 2009. [acessado 2011 jun 13]. Disponível em: http://www.asbran.org.br/sitenovo/arquivos/resolucao38.pdf

3. Torres AL. A saúde bucal coletiva sob a ótica de professores da rede estadual de ensino de São Paulo [dissertação]. São Paulo: Faculdade de Saúde Pública, Universidade de São Paulo; 2002.

4. Marinho FCM, Assao TY, Cervato-Mancuso AM. Percepções e práticas dos diretores e coordenadores acerca da alimentação infantil em creches públicas do município de Jandira, São Paulo, Brasil. Seguranca Alimentar e Nutricional 2010; 17(2):40-49.

5. Gomes DM, Bastos KPL, Souza ECG, Paixão JA, Aredes EM. O papel da escola na formação do bom hábito alimentar. Rev. Cien. da Faminas 2005; 1(1):28

6. Brasil. Ministério da Educação (MEC). Conselho Nacional de Educação. Diretrizes curriculares nacionais para o curso de graduação em pedagogia, licenciatura - Resolução CNE/CP no 1 . Brasília (DF): MEC; 2006.

7. Shimabukuro EE, Oliveira MN, Taddei JAAC. Conhecimentos de educadores de creches sobre alimentação infantil. Rev Paul Pediatr 2008; 26(3):231237.

8. Martins J, Veríssimo MDLOR. Conhecimentos e práticas de trabalhadoras de creches municipais relativos ao cuidado da criança com infecção respiratória aguda. Interface Comun Saúde Educ 2006; 10(20):487-504.

9. Toloni MHA, Longo-Silva G, Goulart RMM, Taddei JAAC. Introdução de alimentos industrializados e de alimentos de uso tradicional na dieta de crianças de creches públicas no município de São Paulo. Rev Nutr 2011; 24(1):61-70.

10. Konstantyner T, Taddei JAAC, Oliveira MN, Palma $D$, Colugnati FAB. Riscos isolados e agregados de anemia em crianças frequentadoras de berçários de creches. J Pediatr 2009; 85(3):209-216.

11. Beghin I. Selecting specific nutrition intervention for incorporation into rural development projects Philipp J Nutr 1983; 36(3):106-114.

12. Universidade Federal de São Paulo (UNIFESP). Nutrição e saúde de lactentes: treinamento para educadores e gerentes de creches. São Paulo: Pró-Reitoria de Extensão da UNIFESP; 2007.

13. Taddei JAAC, Brasil ALD, Palma D, Moraes DEB, Ribeiro LC, Lopez FA. Manual CrechEficiente: guia prático para educadores e gerentes. 2a Edição. Barueri: Minha Editora; 2008.
14. Queiroz DT, Vall J, Souza AMA, Vieira MFC. Ob servação participante na Pesquisa qualitativa: conceitos e aplicações na área da saúde. $R$ Enferm UERJ 2007; 15(2):276-283.

15. Oliveira TRPR, Radicchi ALA. Inserção do nutricionista na equipe de atendimento ao paciente em reabilitação física funcional. Rev Nutr 2005; 18(5):601-611.

16. Westphal MF, Bógus CM, Faria MM. Grupos focais: experiências precursoras em programas educativos em saúde no Brasil. Boletín de la Oficina Sanitaria Panamericana (OSP) 1996; 120(6):472-82.

17. Borges CD, Santos MA. Aplicações da técnica do grupo focal: fundamentos metodológicos, potencialidades e limites. Rev. SPAGESP 2005; 6(1): 74-80.

18. Lervolino AS, Pelicioni MCF. A utilização do grupo focal como metodologia qualitativa na promoção da saúde. Rev Esc Enf USP 2001; 35(2):115-121.

19. Nogueira-Martins MCF, Bógus CM. Considerações sobre a metodologia qualitativa como recurso para o estudo das ações de humanização em saúde. Saúde Soc 2004; 13(3):44-57.

20. Saldiva SRDM, Escuder MM, Mondini L, Levy RB, Venancio SI. Práticas alimentares de crianças de 6 a 12 meses e fatores maternos associados. J Pediatr 2007; 83(1):53-58

21. Caetano MC, Ortiz TT, da Silva SG, de Souza FI, Sarni RO. Complementary feeding: inappropriate practices in infants. J Pediatr 2010; 86(3):196-201.

22. Longo-Silva G, Toloni MHA, Goulart RMM, Taddei JAAC. Avaliação do consumo alimentar em creches públicas e filantrópicas em São Paulo, Brasil. Rev Paul Pediatr. 2012; 30(1):35-41.

23. Holland CV, Szarfarc SC. Consumo energético de pré-escolar de creches. Rev Nutrire 2003; 25:61-70.

24. Zacarelli EM, Philippi ST. Avaliação de momentos da refeição em creches. Rev Nutrire 2006; 30:17-29.

25. Assao TY, Cervato-Mancuso AM. Alimentação saudável: percepção dos educadores de instituições infantis. Rev bras crescimento desenvolv hum 2008; 18(2):126-134.

26. Dias LT, Nascimento DDG, Marcolino FF. O cuidado com a alimentação infantil na visão de profissionais da estratégia saúde da Família e cuidadores familiares. Rev. APS 2010; 13(3):266-276

Artigo apresentado em 10/04/2012

Aprovado em 21/08/2012

Versão final aprovada em 14/09/2011 